\title{
The Self-Propagating High Temperature Synthesis of Titanium Aluminides: A Parametric Study
}

\author{
M. Adeli ${ }^{1}$, S.H. Seyedein ${ }^{1}$, M.R. Aboutalebi ${ }^{1}$, M. Kobashi ${ }^{2}$, N. Kanetake ${ }^{2}$ \\ ${ }^{1}$ School of Metallurgy \& Materials Engineering, Iran University of Science and Technology (IUST), Narmak, Tehran \\ 16844-13114, Iran \\ adelim@iust.ac.ir \\ ${ }^{2}$ Department of Materials Science and Engineering, Graduate School of Engineering, \\ Nagoya University, Furo-cho, Chikusa-ku, Nagoya 464-8603, Japan
}

\begin{abstract}
The present work reports experimental studies on self-propagating high-temperature synthesis of titanium aluminides. Powder mixture of different Ti:Al atomic ratios were adopted and pressed to make compacts. The compacts were heated up to the ignition temperature from one end using induction heating, giving rise to self-sustaining reaction along the compacts. The propagation of reaction front was monitored using a color CCD camera. X-ray Diffraction analyses showed that the main products constituents were $\mathrm{TiAl}, \mathrm{Ti}_{3} \mathrm{Al}$ and $\mathrm{TiAl}_{3}$ in the case of $\mathrm{Ti}: \mathrm{Al}$ atomic ratios of 1:1, 3:1, and 1:3, respectively; rapid preheating to temperatures close to ignition temperature resulted in minimization of the occurrence of undesired phases. The effects of various parameters such as the green compact density and titanium particle size on the ignition time, combustion wave velocity, and combustion temperature were studied.
\end{abstract}

Keywords: Combustion synthesis, titanium aluminides, green density, titanium particle size

\section{Introduction}

Titanium aluminides have attracted considerable attention in research studies during the past decades. Their attractive high-temperature mechanical properties such as excellent creep resistance and high temperature resistance to corrosion, as well as their low density and high specific strength, has made them interesting for future technological applications, especially in aerospace fields [1].

The preparation of titanium aluminides is usually carried out by conventional melting and casting processes [1]. However, due to lack of room temperature ductility in the products and the difficulty of their production by conventional methods, attempts have been made to apply suitable alternative production methods in order to overcome fabrication limitations as well as improve the product properties.

Combustion synthesis is a novel synthesis method which utilizes the exothermic heat of a reaction to make the reaction propagate in a self-sustaining manner through the reactants. This method has been applied to prepare a large number of inorganic materials including intermetallic compounds and their composites [2-6].

The preparation of intermetallic compounds using combustion synthesis has been accomplished by two modes: selfpropagating (SHS) mode and thermal explosion (TE) mode. In the former, a compacted powder mixture is ignited at one end and the reaction propagates through the compact in the form of a combustion front. In the latter, the powder mixture is heated up in a furnace until the onset of the reaction between the reactants [7].

The combustion synthesis of aluminides, in particular nickel aluminides has been broadly investigated [7-14]. However, the combustion synthesis of titanium aluminides especially in self-propagating mode is often faced with major difficulties because of the low enthalpy changes of the exothermic reactions between elemental powders of aluminum and titanium. According to a proposed empirical criterion, an exothermic reaction would not become self-sustaining unless the adiabatic temperature $\left(\mathrm{T}_{\mathrm{ad}}\right)$ is greater than $1800 \mathrm{~K}$. The adiabatic temperature is defined as the maximum temperature reached in the combustion front under adiabatic conditions. Considering this criterion, the production of TiAl by direct SHS is not favorable as the adiabatic temperature in this system is less than $1800 \mathrm{~K}\left(\mathrm{~T}_{\mathrm{ad}}=1518 \mathrm{~K}\right.$ [15]). For such a system, the commonly practiced approach is to preheat the reactants before ignition which increases the adiabatic temperature, or to heat the reactants with a high heating rate to a point where the reaction takes place over the entire sample 
simultaneously, i.e., thermal explosion mode [3]. These alternative methods, however, are not preferable because of the formation of undesirable pre-combustion phases and impure, multiphase products. On the other hand, preheating of the compacted powders prior to ignition cannot be easily performed because of the high reactivity of titanium and aluminum.

The present work was undertaken to experimentally investigate the SHS of three important intermetallic compounds in the Ti-Al binary system, namely, $\mathrm{TiAl}, \mathrm{Ti}_{3} \mathrm{Al}$ and $\mathrm{TiAl}_{3}$, using compressed samples made from elemental powders. A novel method has been utilized for simultaneous preheating and igniting of the sample by induction. Rapid preheating to temperatures close to ignition temperature resulted in minimization of the occurrence of undesired phases. The effects of various parameters such as the initial compact density and titanium particle size on the combustion wave velocity and combustion temperature were studied.

\section{Experimental}

Pure Al (99.99 wt\% pure, <45 $\square \mathrm{m}$ ) and pure Ti (99.9\%) with particles sizes of $10 \square \mathrm{m},<45 \square \mathrm{m}$ and $90-150 \square \mathrm{m}$, were used as the starting powders. The powders were obtained from High-Purity Chemicals, Japan. Appropriate amounts of $\mathrm{Al}$ and $\mathrm{Ti}$ powders were weighed out to the compositions of $\mathrm{Ti}-50 \mathrm{at} \% \mathrm{Al}$, Ti-25at\% Al and Ti-75at\%Al. The powder mixtures were thoroughly hand mixed for 10 minutes. Weighed portions of the mixtures were pressed under the pressure of $10-12 \mathrm{kN}$ to form cylindrical compacts with different diameters of $10 \mathrm{~mm}, 15 \mathrm{~mm}, 18 \mathrm{~mm}$ and $25 \mathrm{~mm}$, and height of $25-$ $30 \mathrm{~mm}$. In order to investigate the effect of sample green density on the synthesis process, samples were prepared with relative densities of 55,60,65, 70 and $75 \%$. To accommodate the placement of two thermocouples, two $1 \mathrm{~mm}$-in-diameter and $2 \mathrm{~mm}$-in-depth holes were drilled with a distance of 3-5mm from the upper and lower bases of the samples.

An experimental setup was designed and prepared to conduct the experiments, as shown in Fig. 1. The samples were held in a chamber through which argon was flowing. All the experiments were conducted under a constant argon flow rate of $1.5 \mathrm{l} / \mathrm{min}$. First light criterion was used to determine the ignition time. The reaction rate was calculated by tracking the reaction front as a function of time.

The preheating and ignition stages were conducted utilizing a steel part heated by an induction coil (SK Medical Electronics Co. Ltd., MU-1700D, Japan) with a maximum power of $4 \mathrm{~kW}$ and maximum voltage of $200 \mathrm{~V}$. The electrical power was immediately turned off after the initiation of the combustion reaction. Two R-type thermocouples connected to an electronic data acquisition system (KEYENCE NR-600 Data Logger, Japan) capable of recording 10signals/s were used to record the temperature history at two certain points within the sample. A color CCD video camera (SONY - DSC W7) was used to monitor the combustion process. X-ray diffraction techniques were employed using a Rigaku RINT-2200 diffractometer to determine the phase composition of the reacted samples.

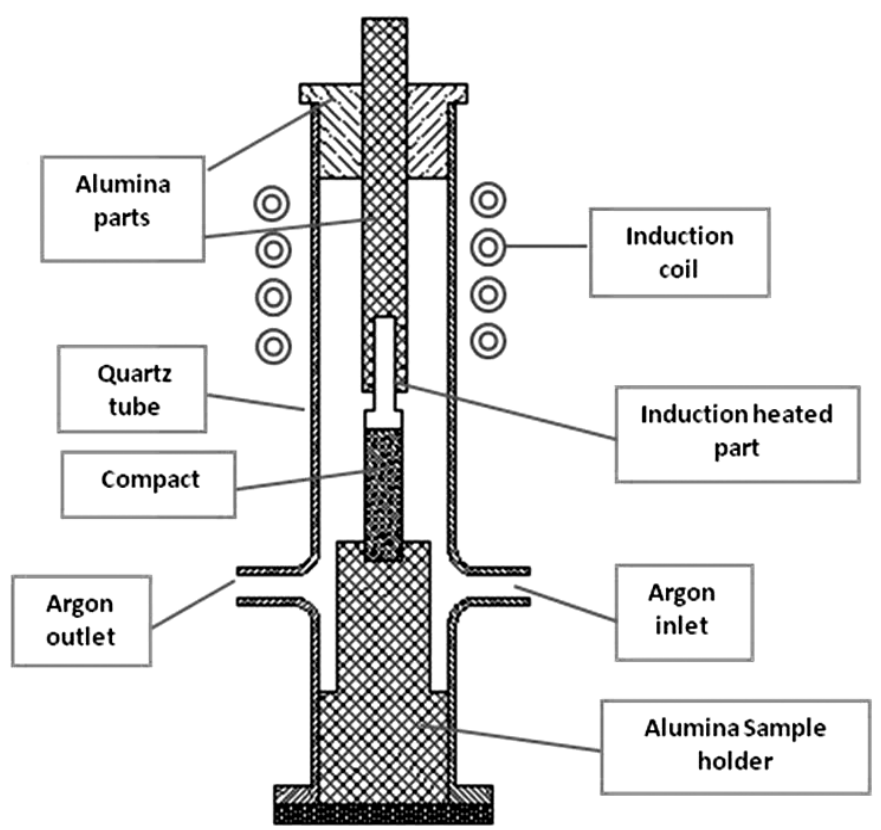

Fig. 1: Schematic representation of experimental setup for synthesis of TiAl by SHS. 


\section{Results and Discussion}

Due to the relatively low exothermicity of the formation reactions of titanium aluminides, conventional ignitors such as hot tungsten wire could not be successfully used to initiate the reaction without preheating. Even if the exothermic reaction happened in the first surface layers subjected to the ignition by conventional ignitors, it would not show a selfsustaining behavior and would be extinguished before completion. Thus in the present study, an induction heating technique was used to preheat and ignite the sample simultaneously. This method has the capability of rapid heating of the whole sample, bringing it to the required preheating temperature as well as providing necessary amount of energy for starting the exothermic reaction at the surface.

The observations in the current study indicated that the combustion front associated with the synthesis of titanium aluminides could propagate in a steady manner. Fig. 2 shows a typical SHS process recorded from the combustion of a Ti$75 \mathrm{at} \% \mathrm{Al}$. As can be seen, after the initiation of the reaction, the reaction front propagated downward, leaving behind the combustion product. The wave velocities in the Ti-Al system are much lower than those reported in several research studies for the production of other aluminides $[13,16]$. In most of the experiments, it took approximately 8-10s for the reaction wave to travel along the sample depending on the sample length and its composition. The product remained glowing for another 5-10s, and then it began to cool down due to heat loss to the surroundings. Most of the samples did not experience any severe deformation during the synthesis process and only a slight expansion was observed.

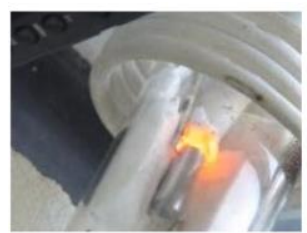

$30 \mathrm{~s}$

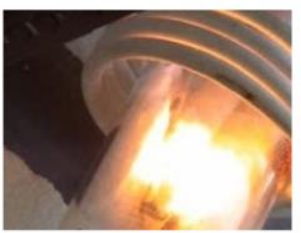

$49 \mathrm{~s}$

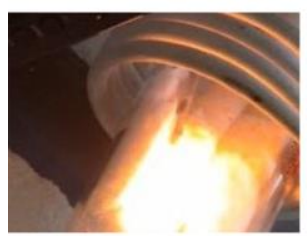

$55 \mathrm{~s}$

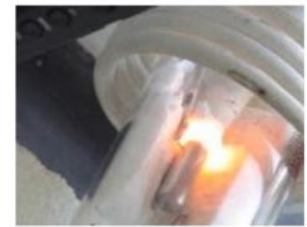

$40 \mathrm{~s}$

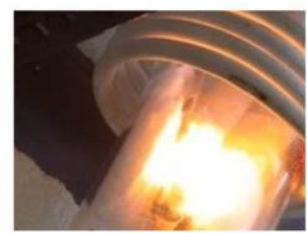

$50 \mathrm{~s}$

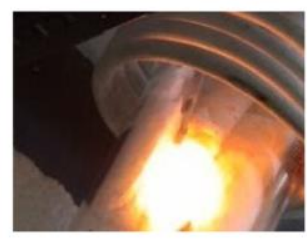

$60 \mathrm{~s}$

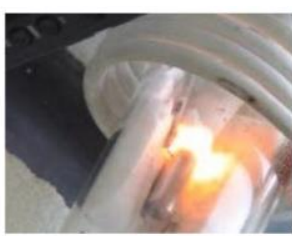

$45 \mathrm{~s}$

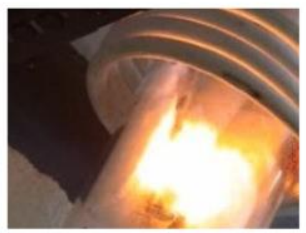

$51 \mathrm{~s}$

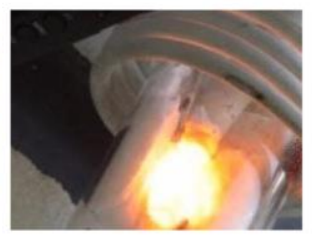

$70 \mathrm{~s}$

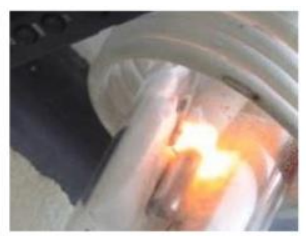

$46 \mathrm{~s}$

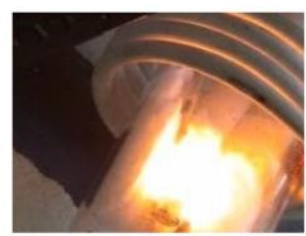

$52 \mathrm{~s}$

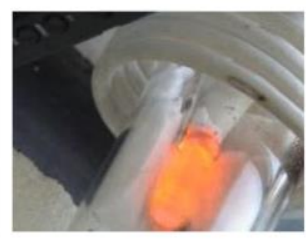

$80 \mathrm{~s}$

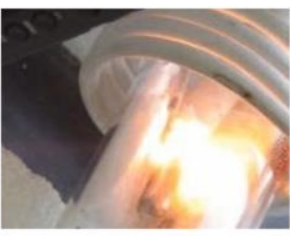

$47 \mathrm{~s}$

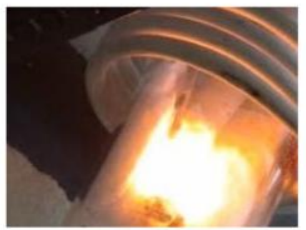

$53 \mathrm{~s}$

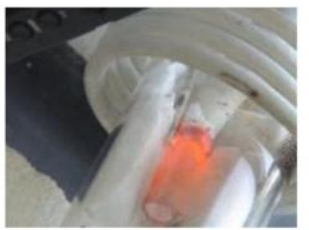

$90 \mathrm{~s}$

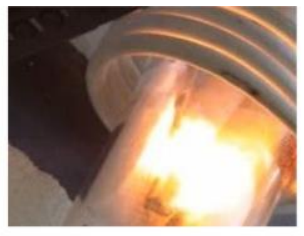

$48 \mathrm{~s}$

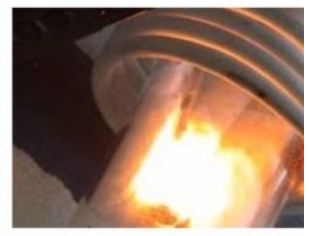

$54 \mathrm{~s}$

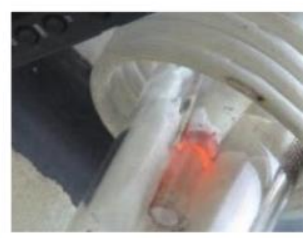

$100 \mathrm{~s}$

Fig. 2: Images of flame propagation in the SHS reaction in a compact consisting of Ti-75 at $\% \mathrm{Al}$ with relative density of $70 \%$.

Typical temperature history results during the synthesis of the samples are shown in Fig. 3. In this figure, the first stage of the diagram indicates the linear heating caused by induction. The upper sections of the samples were much more influenced by induction heating, and hence the preheating temperature at the upper part of the sample, indicated by thermocouple1, was higher than that of the lower parts. Once the reaction started, the electrical power was turned off and an abrupt temperature rise occurred in the sample due to the heat released by the reaction. The temperature reached to a maximum very fast. Finally, the sample was cooled to room temperature by radiation and convection heat transfer to the surroundings. The maximum temperature $\left(\mathrm{T}_{\mathrm{C}}\right)$ could be determined from the measured temperature-time curves. 


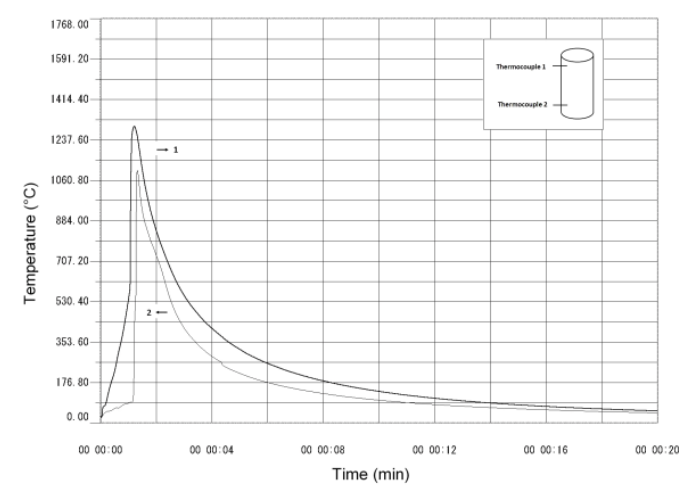

Fig. 3: Typical temperature histories recorded by thermocouples embedded in two different points of a Ti-50at\%Al sample with relative density of $65 \%$.

Typical temperature histories obtained at the same operational conditions for the synthesis of $\mathrm{TiAl}, \mathrm{Ti}_{3} \mathrm{Al}_{\mathrm{l}}$ and $\mathrm{TiAl}_{3}$ are compared in Fig. 4. Based on the reaction model first proposed by Alexandrov et al. [17] and generally accepted in the combustion synthesis of aluminide intermetallic compounds [9, 19, 20], aluminum melts as soon as the temperature approaches its melting point. The molten aluminum spreads and engulfs the higher melting particles and a thin film of an intermediate phase forms around them. Further diffusion across this intermediate layer results in the formation of the final product by precipitation from the saturated liquid. Considering this mechanism, it was expected that the increasing of aluminum content in the system should result in the increasing of combustion temperature as more aluminum melt comes in contact with titanium particles. In contrast, the combustion temperatures in the synthesis of TiAl were generally slightly higher than the other two compounds in normal conditions. This could be due to the higher exothermic heat of formation of TiAl compared to those of $\mathrm{Ti}_{3} \mathrm{Al}$ and $\mathrm{TiAl}_{3}$ according to Hahn and Lee [20]. Under similar heat loss conditions, the exothermic heat of reaction is directly related to the adiabatic and therefore the combustion temperatures.

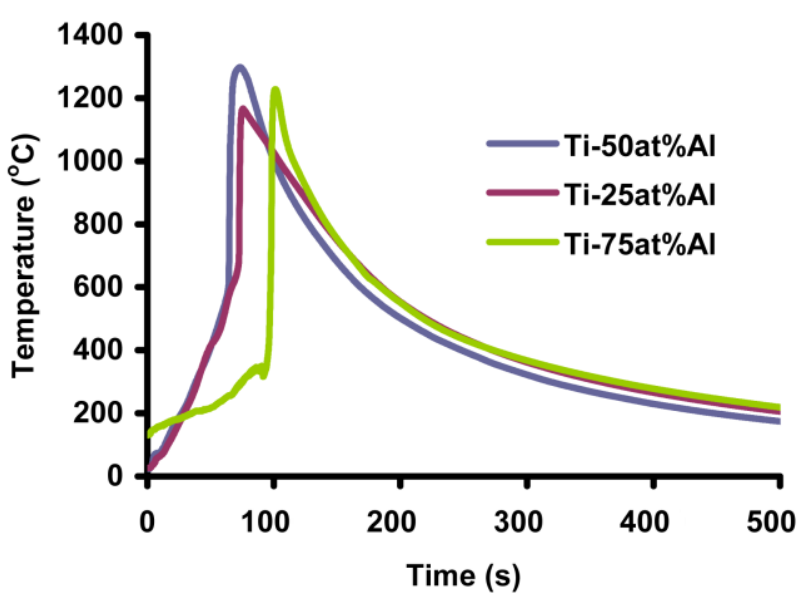

Fig. 4: Typical time-temperature curves for the synthesis of $\mathrm{TiAl}, \mathrm{Ti}_{3} \mathrm{Al}$, and $\mathrm{TiAl}_{3}$ as recorded by thermocouple 1 (relative density: $65 \%, \mathrm{D}=10 \mathrm{~mm})$.

X-ray diffraction patterns of the combustion synthesis products for all three atomic ratios showed that the main constituent of the product in each case is the related titanium aluminide phase, i.e. TiAl for Ti-50at\%Al powder mixture, $\mathrm{Ti}_{3} \mathrm{Al}$ for $\mathrm{Ti}-25 \mathrm{at} \% \mathrm{Al}$, and $\mathrm{TiAl}_{3}$ for $\mathrm{Ti}-75 \mathrm{at} \% \mathrm{Al}$ powder mixture. This was the case for all the examined samples subjected to XRD analysis.

The effect of such parameters as green porosity and titanium particle size on the wave propagation and combustion temperature as well as the time- to-ignition was evaluated for the synthesis of $\mathrm{TiAl}_{1} \mathrm{Ti}_{3} \mathrm{Al}$ and $\mathrm{TiAl}_{3}$. Fig. 5 illustrates the effect of compact relative density on the combustion temperature for the synthesis of the three intermetallic compounds. 

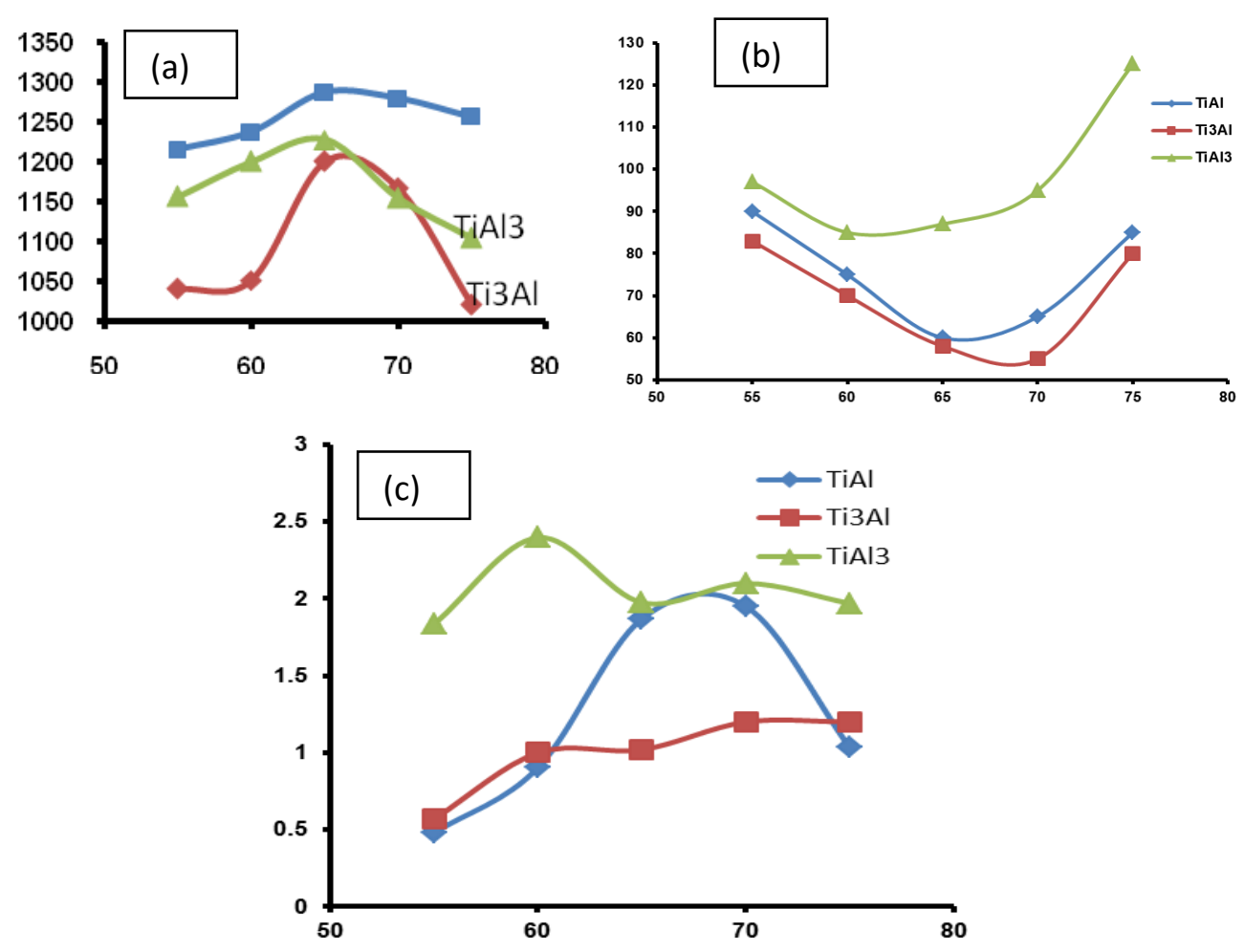

Fig. 5: The effect of compact density on (a) combustion temperature, (b) ignition time, and (c) reaction front velocity.

As can be seen from this figure, the variation of combustion temperature with relative density follows similar trend in the synthesis of all three compounds. An increase in the relative density in the range of 55 to $65 \%$ results in an increase in combustion temperature, which could be due to enhanced effective contact between particles and improved conductivity. The highest combustion temperature in all three systems is obtained with relative density of $65 \%$. However, further increase in the relative density of green compacts results in excessive contact between the particles, leading to fast dissipation of heat from the reaction front, further deviations from adiabatic conditions, and lower combustion temperatures. More drastic changes are observed in the synthesis of $\mathrm{Ti}_{3} \mathrm{Al}$, which may be because of lower aluminum content of the system, making the system more sensitive to the amount of porosity. Too low relative densities lead in remarkable loss of contact between titanium and aluminum powders. In case of too high relative densities, the spreading of aluminum melt among the voids is faced with more difficulties in this particular system. Therefore, obtaining the optimum heat flow rate seems to be more marginal.

The variation of ignition times with relative density is shown in Fig. 5(b). In higher relative densities, the enhancement of the compact conductivity results in higher heat transfer rate to the surroundings and to the layers below the surface layers subjected to ignition. Therefore, longer times are needed to heat up the compact surface up to ignition temperature $\left(\mathrm{T}_{\mathrm{ig}}\right)$.

It should be noted that much higher ignition times were usually needed in the case of $\mathrm{TiAl}_{3}$ formation. The high value of heat conductivity of aluminum causes the compact heat resistance to decrease, which makes the heat be rapidly drawn away from the surface layers compared to the other two powder compositions, and much more time is required by the heat source to ignite the surface. This effect seems to become more significant in higher relative densities.

The propagation rate of combustion reaction was calculated based on the time taken for the passage of the reaction front between the two thermocouples. The observations of reaction progress from flame propagation images confirmed the evaluated velocity (Fig. 2). The effect of green density on the propagation rate is shown in Fig. 5(c). Similarly, too high or too low amounts of porosity usually had adverse effect on the propagation rate, and the maximum propagation rates were obtained in relative densities of 65 to $70 \%$ for TiAl compound, and around $60 \%$ for $\mathrm{TiAl}_{3}$ compound. However, the initial relative density did not affect the propagation rates in the synthesis of $\mathrm{Ti}_{3} \mathrm{Al}$ to any significant level. In constant densities, 
the propagation rates in the synthesis of $\mathrm{TiAl}_{3}$ was usually higher than the other two, which is attributed to the presence of more liquid phase resulting in the enhancement of mass transfer phenomena.

All of the $\mathrm{Ti}_{3} \mathrm{Al}$ and $\mathrm{TiAl}_{3}$ products examined in the present work showed even distribution of pores in their final structure. In the case of TiAl, signs of melting of surface layers as well as non-uniformity in the distribution of pores were observed. This is typically demonstrated in Figs. 6(a) to 6(c), in which longitudinal sections of the products are given. A relative peripheral accumulation of pores can be seen in the TiAl products in the regions close to the outer wall. The $\mathrm{TiAl}_{3}$ products possessed the highest amount of pores distributed throughout the sample, a portion of which is incorporated as a result of presence of higher percentage of liquid phase within the sample during the process. In the case of $\mathrm{Ti}_{3} \mathrm{Al}$, production of samples presenting very good cross sections was achieved due to their lower aluminum content and minimum melting occurred during the synthesis process.

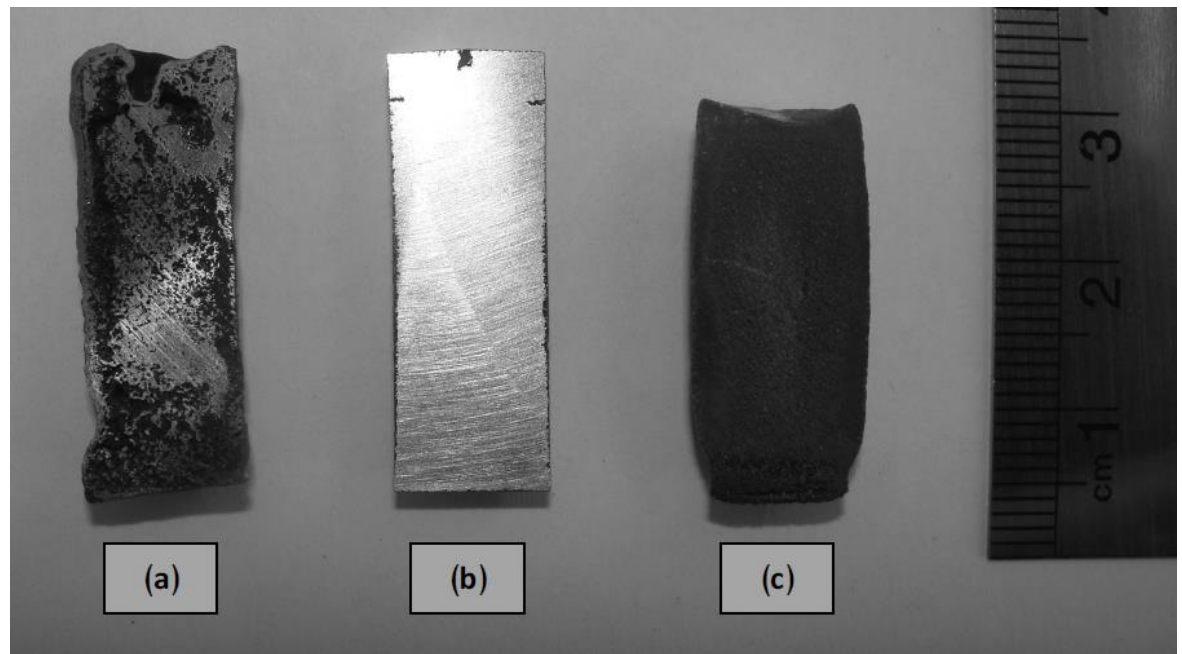

Fig. 6: Longitudinal section of the products showing the distribution of pores, (a) TiAl, (b) $\mathrm{Ti}_{3} \mathrm{Al}$ (c) $\mathrm{TiAl}_{3}$.

Table 1: The effect of titanium particle size on the combustion synthesis parameters for mixtures of Ti-50at\% Al, Ti-25at\% Al and Ti$75 \mathrm{at} \% \mathrm{Al}$ (relative density: 65\%, D=10mm).

\begin{tabular}{|c|c|c|c|c|c|c|c|c|c|}
\hline \multirow{2}{*}{$\begin{array}{c}\text { Titanium } \\
\text { particle } \\
\text { size }\end{array}$} & \multicolumn{3}{|c|}{ Combustion temperature $\left(\mathbf{T}_{c}\right)$} & \multicolumn{3}{|c|}{ Ignition time $\left(t_{i g}\right)$} & \multicolumn{3}{|c|}{ Reaction front velocity $\left(V_{c}\right)$} \\
\hline & $\begin{array}{c}\text { Ti- } \\
\text { 50at\%Al }\end{array}$ & $\begin{array}{c}\text { Ti- } \\
\text { 25at\% Al }\end{array}$ & $\begin{array}{c}\text { Ti- } \\
\text { 75at\%Al }\end{array}$ & $\begin{array}{c}\text { Ti- } \\
\text { 50at\%Al }\end{array}$ & $\begin{array}{c}\text { Ti- } \\
\text { 25at\%Al }\end{array}$ & $\begin{array}{c}\text { Ti- } \\
\text { 75at\% Al }\end{array}$ & $\begin{array}{c}\text { Ti- } \\
\text { 50at\% Al }\end{array}$ & $\begin{array}{c}\text { Ti- } \\
\text { 25at\%Al }\end{array}$ & $\begin{array}{c}\text { Ti- } \\
\text { 75at\% Al }\end{array}$ \\
\hline$<10 \mathrm{~mm}$ & 1200 & 1089.6 & 1145.3 & 27 & 27 & 30 & 6.06 & 2.0 & 3.04 \\
\hline$<45 \mathrm{~mm}$ & 1287.6 & 1200.5 & 1227.5 & 60 & 58 & 87 & 1.88 & 1.02 & 1.97 \\
\hline $90-150 \mathrm{~mm}$ & 1213.35 & 1198 & 1190 & 90 & 85 & 155 & 0.6 & 0.75 & 2.37 \\
\hline
\end{tabular}

Since the dissolution of the higher-melting elements in molten aluminum pool is one major kinetic step in the combustion synthesis of aluminide intermetallic compounds, the particle/melt interface plays an important role in the dissolution process. As shown in Table 1, using finer titanium particles yields much higher propagation velocities implying better interfacial contact between titanium particles and aluminum melt, shorter diffusion distances, and enhanced dissolution of solid titanium into liquid phases. On the contrary, increasing the titanium particle size and decreasing of the interfacial contact surface develops a high kinetic barrier in the reaction progress leading to lower propagation velocities and greater times required to initiate the reaction. An exception of this was the synthesis of $\mathrm{TiAl}_{3}$ using coarse - grained titanium. It took a very long time to ignite the sample; once ignited, the reaction front propagated at a very high rate. This could be the result of applying the induction heat source for too long for initiating the reaction, which provided enough time to bring all the portions of the sample to high preheating temperatures close to the melting point of aluminum, causing 
the reaction to propagate very fast all over the sample after being ignited. The variation of combustion temperature with titanium particle size did not seem to follow any determinable trend.

\section{Conclusion}

The combustion synthesis of powder mixtures of Ti-25at\%Al, Ti-50at\%Al, and Ti-75at\%Al by the self-propagation combustion synthesis was investigated. The front propagation velocity and the combustion temperature profile were affected by the aluminum content of the system, volume fraction of porosity, and titanium particle size. The effect of relative density on the ignition time and reaction propagation is the result of a balance between good particle contact and not too high thermal conductivities to result in excessive heat loss from the reaction zone. The optimum value of relative density was determined to be in the range of $60-70 \%$. Using smaller Ti particles kinetically stimulated the combustion reaction, leading to much higher propagation velocities and lower ignition times. The variations of combustion temperature with titanium particle size did not follow any detectable trend.

\section{References:}

[1] F. H. Froes, C. Suryanarayana, and D. Eliezer, "Synthesis, properties and applications of titanium aluminides," $J$. Mater. Sci., vol. 27, pp. 5113-5140, 1992.

[2] A. G. Merzhanov, "Combustion processes that synthesize materials," J. Mater. Proc. Tech., vol. 56, pp. 222-241, 1996.

[3] Z. A. Munir and U. Anselmi-Tamburini, "Self-propagating exothermic reactions," Mater. Sci. Rep., vol. 3, pp. 277$365,1989$.

[4] A. Varma and J. P. Lebrat, "Combustion synthesis of advanced materials," Chem. Eng. Sc., vol. 47, pp. 2179-2194, 1992.

[5] J. B. Holt and S.D. Dunmead, "Self-heating synthesis of materials," Annu. Rev. Mater. Sci., vol. 21, pp. 305-334, 1991.

[6] J. J. Moore and H. J. Feng, "Combustion synthesis of advanced materials I," Prog. Mater. Sci., vol. 39, pp. 243-273, 1995.

[7] K. A. Philpot, Z. A. Munir, and J. B. Holt, "An investigation of the synthesis of nickel aluminide through gasless combustion," J. Mater. Sci., vol. 22, pp. 159-169, 1987.

[8] A. S. Mukasyan, A. S. Rogachev, and A. Varma, "Mechanism of reaction wave propagation during combustion synthesis of advanced materials," Chem. Eng. Sci., vol. 54, pp. 3357-3367, 1999.

[9] A. Biswas and S. K. Roy, "Comparison between the microstructural evolutions of two modes of SHS of NiAl: key to a common reaction mechanism," Acta Mater., vol. 52, pp. 257-270, 2004.

[10] N. Kanetake and M. Kobashi, "Innovative processing of porous and cellular materials by chemical reaction," Scripta Mater., vol. 54, pp. 521-525, 2006.

[11] Q. Fan, H. Chai, and Z. Jin, "Dissolution-precipitation mechanism of SHS of mononickel aluminide," Intermetallics, vol. 9, pp. 609-619, 2001.

[12] P. Zhu, J. C. M. Li, and C. T. Liu, "Adiabatic temperature of combustion synthesis of Al-Ni systems," Mater. Sci. Eng. A, vol. 357, pp. 248-257, 2003.

[13] C. L. Yeh and C. C. Yeh, "Preparation of CoAl intermetallic compound by combustion synthesis," J. Alloys Comp., vol. 388 , pp. 241-249, 2005.

[14] C. Milanese, F. Maglia, A. Tacca, U. Anselmi-Tamburini, C. Zanotti, and P. Giuliani, "Ignition and reaction mechanism of Co-Al and $\mathrm{Nb}-\mathrm{Al}$ intermetallic compounds prepared by combustion synthesis," J. Alloys Comp., vol. 421, pp. 156-162, 2006.

[15] H. C. Yi, A. Petric, and J. J. Moore, "Effect of heating rate on the combustion synthesis of Ti-Al intermetallic compounds," J. Mater. Sci., vol. 27, pp. 6796-6806, 1992.

[16] C. L. Yeh and W. Y. Sung, "Combustion synthesis of Ni3Al intermetallic compound," J Alloys comp, vol. 384, pp. 181-191, 2004.

[17] V. V. Aleksandrov and M. A. Korchagin, Comb. Expl. Shock Waves, vol. 23, pp. 557-560, 1988.

[18] J. P. Lebrat, A. Varma, and N. E. Miller, Metall Trans A, vol. 23, no. 69, pp. 69-76, 1992. 
[19] G. Xiao, Q. Fan, M. Gu, and Z. Jin, "Microstructural evolution during the combustion synthesis of TiC-Al cermet," Mater. Sci. Eng. A, vol. 425, pp. 318-325, 2006.

[20] Y. D. Hahn and Y. T. Lee, "Combustion synthesis of Ti-Al intermetallic compound," Particul. Mater. Process., vol. 9, pp. 309-318, 1992. 